\title{
Statistical analysis of the weather conditions of the main SSS routes in the Western Mediterranean for its presentation and use as a participatory site web to support learning processes.
}

\author{
F.X. Martínez de Osés ${ }^{1}$, Elisenda Ventura Jariod ${ }^{2}$ \\ ${ }^{1}$ Department of Nautical Science and Engineering. Barcelona School of \\ Nautical Studies. Technical University of Catalonia - BarcelonaTech, Pla de Palau, \\ 18, 08003 Barcelona, Catalonia (Spain) \\ fmartinez@cen.upc.edu \\ 'Barcelona School of Nautical Studies. Technical University of Catalonia - \\ BarcelonaTech, Pla de Palau, 18, 08003 Barcelona, Catalonia (Spain). \\ elisenda.venturadestudiant.upc.edu
}

\begin{abstract}
In the early years, maritime education had been mainly focused on the vocational training of deck officers on board. However, as the maritime business evolved, a change in the maritime education curriculum started to be necessary. To align maritime programs with the needs of maritime stakeholders, maritime studies became an interdisciplinary academic field. Today, MET institutions juggle to comply with the Standard Training and Certificate Watch keeping (STCW) Convention and Code. However, is also important to ensure that core subjects do not fade out under the integration of these new courses. As the emphasis on creating dedicated knowledge arises, students should be encouraged to participate on the researches conducted by their own centers through new participatory forms of web-based communication.

This project has its origins in the research carried out by the Science and Engineering Department (DCEN) of the Nautical Faculty of Barcelona for the optimization of routes in the western Mediterranean. Through the analysis of the weather conditions in the Western Mediterranean sailing area and, in particular, the most common adverse weather conditions in the area, a study of the impact of these weather conditions is carried on in the context of sea route optimization and their importance for short-haul transport. The results of the study are presented in participatory web format for dissemination and use as a didactic tool by the students; the
\end{abstract}




\begin{abstract}
routes studied will also be used as practical examples to explain the contents of the course in a clear and concise way. Through computedsupported collaborative learning, students will acquire life-long skills and they will participate of the activities of their institution.
\end{abstract}

Keywords: Short Sea Shipping, meteorology, web resources.

\title{
1 Introduction
}

The Short Sea Shipping (SSS) market is crucial for our sector, especially in the Mediterranean [1]. However, although the measures taken by the European Union to improve its use have been numerous, these have not been implemented quiet successfully and few routes have their continuity assured; despite the benefits that this mode of transport offers, there are still many reluctances regarding its implementation, that slow down its growth and damage its image [2] [3].

This paper presents the results obtained in the project linked to the research carried out by the Science and Engineering Department (DCEN) of the Barcelona School of Nautical Studies, for the optimization of routes in the western Mediterranean. Through the analysis of the weather conditions in the Western Mediterranean sailing area and, in particular, the most common adverse weather conditions in the area, a study of the impact of these weather conditions is carried on in the context of sea route optimization and their importance for the Short Sea Shipping routes in the area. Furthermore, this project also thrives to become a platform used by the students of the Faculty as a didactic tool for the subject of Meteorology.

There are many publications that establish which are the factors that condition the SSS in the Mediterranean and which impact have for the function of costs of this mode of transport [4] [5]; generally, these articles analyse its efficiency and sustainability [6] [7]. However, some knowledge on climatology and meteorology is key to understand the case that occupies us; the climatology of the Mediterranean has been amply studied by numerous authors [8] [9] [10] and continues being a very present element in the recent academic production [11] [12]. 
The area surveyed, the basin of the western Mediterranean, has also been studied in the last years, especially its characteristics [13] [14] [15]. Its geographic localization makes of the western Mediterranean Sea one font of indispensable resources for Europe's south countries and the north of Africa.

As it has been pinpointed for other authors [16], it results necessary an analyses of the main variables that affect at the SSS in the western Mediterranean to comprehend which is the impact that these characteristic meteorological conditions have on the behaviour of the ship, and for the function of costs, in order to determine the best course at any season of the year.

This study considers one of the principal variables that affect the ship while in navigation: the waves. These are especially important when considering the consumption of fuel that, as it has already been established in literature is the first factor that will affect the variable cost of the SSS [15].

With the data collected through the web of Puertos del Estado1, the main areas of affectation have been defined as well as the changes produced through the seasons have been studied. Once these results have been analysed, they have been contrasted comparing them with the results obtained with the SIMROUTE software2 for one of the routes of SSS of the Mediterranean for each month of the year 2017. The data of this study have been compared with the known parameters of the western Mediterranean to extract the conclusions.

1 Puertos del Estado is the government agency responsible for the coordination and efficiency control of the Port Authorities of the Spanish Port System. On its official web site (http://www.puertos.es/en-us) it can be find, among others, oceanographical information and the reports used in this analysis.

2 The SIMROUTE is software designed for maritime route optimizations which carries out simulations of short and long distances. This software has been developed by a team of researchers at the Technical University of Catalonia (UPC-BarcelonaTech) in MATLAB language. The spatial scope of SIMROUTE is the Mediterranean Sea, fully or partially selected, depending on the longitudes and latitudes introduced by the user. In order to run the program, there are several parameters to introduce: port of departure, port of arrival, vessel speed and the wave field for the days of the voyage to simulate. 
As the information of the meteorology and climatology available for the students does not contain, in most cases, the data used for the studies, it is often difficult for them to work with it. To tackle this problem and provide the students with appropriate materials to fully understand the contents of the subject, the results of this study have been presented in participatory web format for dissemination and use as a didactic tool by them; the routes studied will also be used in class as practical examples to explain the contents of the course in a clear and concise way.

\section{$2 \quad$ Materials and Methodology}

The pool of data analysed for this survey, nicknamed SIMAR, is made of some temporal series of parameters for waves numerically modelled; they are, therefore, synthetic data.

This pool of data arises from the concatenation of the two big pools of data simulated by Puertos del Estado, SIMAR-44 and WANA, and offer an extensive temporal series, updated and generated with a time cadence for the period 1958-2017.

The temporal stretch, together with its regularity, is the main reason for which this pool of data has been chosen instead of the data collected by the buoys placed near the coast. Although the latter offers real data, its proximity to the coast and the disparity among periods studied, make difficult to establish the pool of data to study. However, even when the pool of data SIMAR, presents a more limited and artificial, offers a wider period that results more suitable for a statistical survey of the climatological variables.

The reports studied presented the statistical characterization of the waves, in the medium term; the reports were completed with a statistical description of the series of heights, periods and directions of the waves. Three types of statistics were included for the waves: height and period distributions, wave roses, and height and wave direction distributions. 
This survey has centred especially at the distributions of height and period to find a relation between the seasonal climate and the behaviour of the waves. However, the direction of the waves has been observed in order to determine which is the most repetitive.

To analyse the data the following methodology has been established:

1. Selection of the points SIMAR, distributed at the basin of the wester Mediterranean, considering their geographic situation. Some of them, after being considered, have been disregarded for being too close to the coast.

2. Selection of the meteorological variables. This survey has considered the significant height $(\mathrm{Hs})$ at $\%$ and the direction of the swell, since they are the parameters that most influence when navigating.

3. Sorting of the data according to seasons and zones established.

4. Tabulation and elaboration of seasonal graphs for each zone.

5. Calculus of the average distribution for season and zone.

6. Determination of the behaviour of the variables selected at the period studied.

7. Weighting of the data by seasons and zones to establish which challenges do they pose for the SSS lines.

8. Obtention of the differences of time and fuel for the route studied for the cases of the optimal route and the minimal distance route.

9. Comparative of the results obtained through the statistical analysis of the conditions with the interpolated wave fields generated with the SIMROUTE software for the days chosen. 
The available data for each point studied, regarding its annual distribution along the period 1958-2017, have been considered in order to establish distinct zones that presented a similar behaviour. From there, the basin of the western Mediterranean has been divided in four zones: the area 1 (in green), the area 2 (in lilac), the area 3 (in yellow) and the coastal area (in blue) (see Fig.1). This last area is formed by points that, due to their proximity with the coast, showed a characteristic distribution that could induce errors if considered together with the points of the other areas. Therefore, the areas studied are limited to the first three.

Although initially the identification of each one of the points resulted crucial for their classification, once established the zones, the points have been treated as a data set.

Finally, the program SIMROUTE has been run for the route BarcelonaGenova for the days 13 and 14 of each month of the year 2017. The analysis has considered the interpolated wave areas for the zone studied for each month, in order to check if the real data resembled the statistics.

The results have been compared among them and with the data of swell analysed for each season to establish similarities and/or dissidences. 


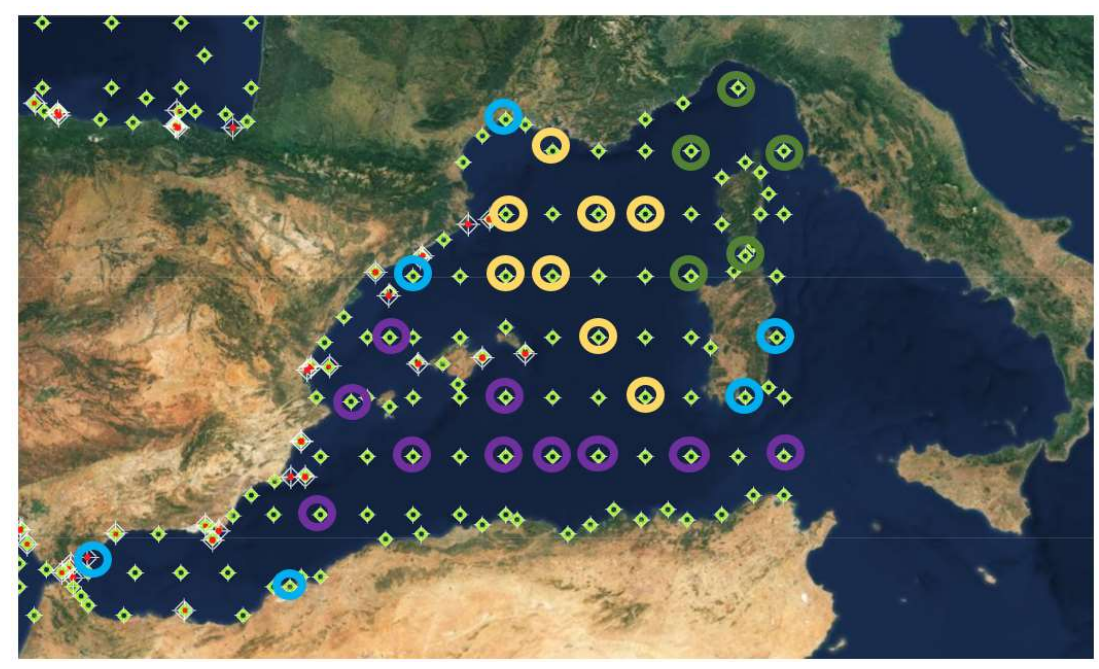

Fig. 1. Distribution of the points SIMAR studied.

\section{$4 \quad$ Results}

The following tables (Table 1, Table 2, Table 3) show the average distribution for each season at the defined areas of the western Mediterranean.

Studying the seasonal behaviour, it is observed that all three areas show a similar evolution; in the period comprised between December and February, the percentage of waves with a significant height of more than three metres increases, surpassing the 5 metres, while, in the period comprised from March to May, it the data show that, although the distribution is similar, the incidence of waves with a superior height of 3 metres, diminishes roughly by a $50 \%$, compared with the previous season.

In all of them, in the period comprised by the months of June, July and August, the conditions of the sea improve notoriously, with a decrease of the $40 \%$ of the significant height from 2 metres, in comparison with the previous season. On the other hand, in this same period, increases the incidence of a swell of less than 0,5 metres. Finally, the months of 
September, October and November, show a new increase of the incidence of the swell from 2 metres by a 50\%. However, although the changes of the significant height of the swell are similar across the three areas established, they do not have the same impact on them, since they present distinct characteristics.

It can be appreciated that in the area 1 , there is a swell with a minor significant height arriving, in general, up to 1,5 metres. The area 2 , that has most of its points situated among the $36^{\circ}$ and the $38^{\circ}$ of latitude, presents a significant height of the swell minor than the area 3 , but higher than the area 1 . The area 3 stands up for a higher incidence of significant heights from 2,5 metres to 5 metres, at any epoch of the year, excluding the summer, where waves of 5 meters result almost non-existent in all the areas.

Table.1. Average seasonal Distribution for the area 1.

Significative Height (Hs) en \%

\begin{tabular}{llllllllllll}
\hline Period & $<\mathbf{0 , 5}$ & $\mathbf{1}$ & $\mathbf{1 , 5}$ & $\mathbf{2}$ & $\mathbf{2 , 5}$ & $\mathbf{3}$ & $\mathbf{3 , 5}$ & $\mathbf{4}$ & $\mathbf{4 , 5}$ & $\mathbf{5}$ & $\mathbf{5}$ \\
\hline Dec.-Feb. & 26,65 & 30,53 & 18,77 & 11,17 & 6,21 & 3,32 & 1,71 & 0,88 & 0,41 & 0,19 & 0,17 \\
\hline Mar. - May & 35,62 & 32,73 & 16,31 & 8,05 & 3,86 & 1,85 & 0,85 & 0,39 & 0,18 & 0,08 & 0,07 \\
\hline Jun. - Aug. & 54,32 & 28,48 & 10,12 & 4,33 & 1,75 & 0,64 & 0,24 & 0,07 & 0,02 & 0,01 & 0,00 \\
\hline Sept. - Nov. & 39,24 & 30,34 & 15,30 & 7,96 & 3,88 & 1,85 & 0,80 & 0,35 & 0,16 & 0,06 & 0,05 \\
\hline
\end{tabular}

Table.2. Average seasonal Distribution for the area 2.

Significative Height (Hs) en \%

\begin{tabular}{llllllllllll}
\hline Period & $<\mathbf{0 , 5}$ & $\mathbf{1}$ & $\mathbf{1 , 5}$ & $\mathbf{2}$ & $\mathbf{2 , 5}$ & $\mathbf{3}$ & $\mathbf{3 , 5}$ & $\mathbf{4}$ & $\mathbf{4 , 5}$ & $\mathbf{5}$ & $>\mathbf{5}$ \\
\hline Dec.-Feb. & 15,45 & 27,23 & 21,50 & 14,65 & 9,05 & 5,38 & 3,15 & 1,82 & 0,96 & 0,51 & 0,39
\end{tabular}




\begin{tabular}{lccccccccccc}
\hline Mar. - May & 18,00 & 34,83 & 22,15 & 11,89 & 6,41 & 3,32 & 1,82 & 0,86 & 0,40 & 0,19 & 0,13 \\
\hline Jun. - Aug. & 27,50 & 44,29 & 19,12 & 6,43 & 1,93 & 0,52 & 0,14 & 0,05 & 0,01 & 0,00 & 0,00 \\
\hline Sept. - Nov. & 20,44 & 37,22 & 21,24 & 10,69 & 5,28 & 2,60 & 1,30 & 0,68 & 0,29 & 0,13 & 0,11 \\
\hline
\end{tabular}

Table.3. Average seasonal Distribution for the area 3.

\begin{tabular}{|c|c|c|c|c|c|c|c|c|c|c|c|}
\hline \multirow[b]{2}{*}{ Period } & \multicolumn{11}{|c|}{ Significative Height (Hs) en \% } \\
\hline & $<0,5$ & 1 & 1,5 & 2 & 2,5 & 3 & 3,5 & 4 & 4,5 & 5 & $>5$ \\
\hline Dec.-Feb. & 11,94 & 24,51 & 21,03 & 15,59 & 10,48 & 6,81 & 4,30 & 2,55 & 1,36 & 0,68 & 0,73 \\
\hline Mar. - May & 19,54 & 31,17 & 20,50 & 12,06 & 7,27 & 4,32 & 2,54 & 1,32 & 0,65 & 0,32 & 0,32 \\
\hline Jun. - Aug. & 33,78 & 32,76 & 15,12 & 7,58 & 3,96 & 1,92 & 0,73 & 0,27 & 0,09 & 0,03 & 0,01 \\
\hline Sept. - Nov. & 21,25 & 29,99 & 20,17 & 12,51 & 7,41 & 4,12 & 2,20 & 1,17 & 0,57 & 0,27 & 0,33 \\
\hline
\end{tabular}

Comparing these data with the interpolated waves area generated by the SIMROUTE for the days selected of each month, a similar behaviour can be observed. From the months of December to January, the swell represented has a height of 2-3 metres and, in some points, it arrives up to 5 metres (Fig. 2). Conversely, for the months from March to May, the height of the waves diminishes gradually, never surpassing the 3,5 metres (Fig. 3). From June to August, the season that presents the best conditions, the swell does not surpass the 2 metres, with certain exceptions in some points close to Corse in July. Lastly, whereas September and October present some similar conditions compared with the period of March-May, November presents an increase at the height of the swell, especially in the area 2, that would correspond at a maritime storm, very common in this month of the year. 


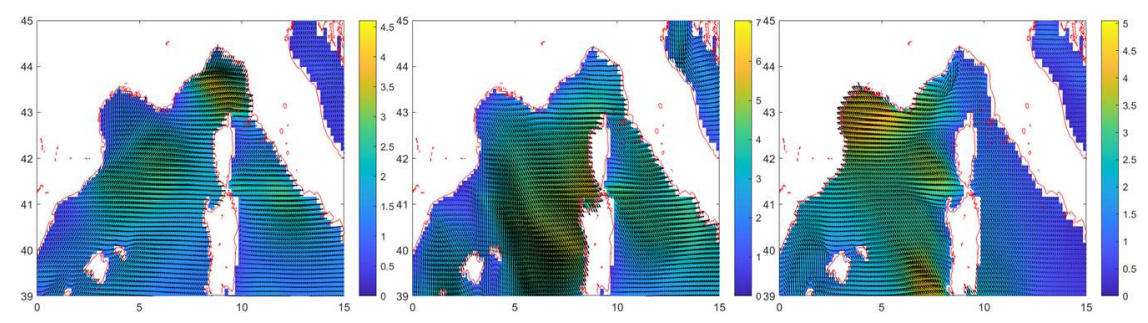

Fig.2. December - January - February.

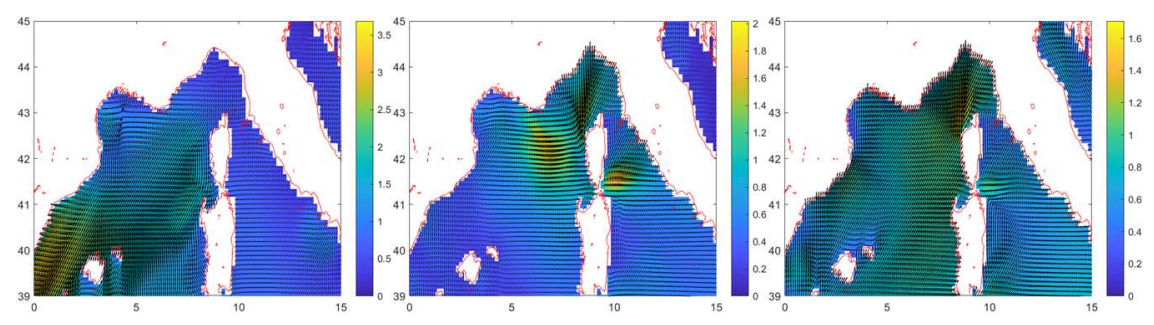

Fig.3. March - April - May.

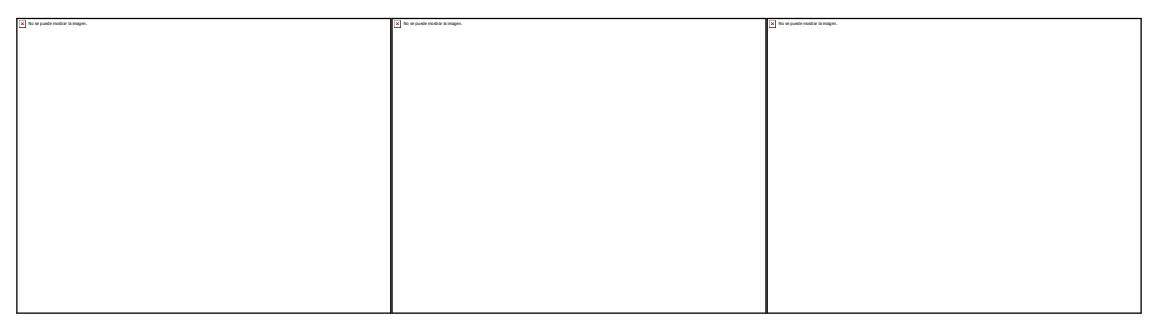

Fig.4. June - July- August.

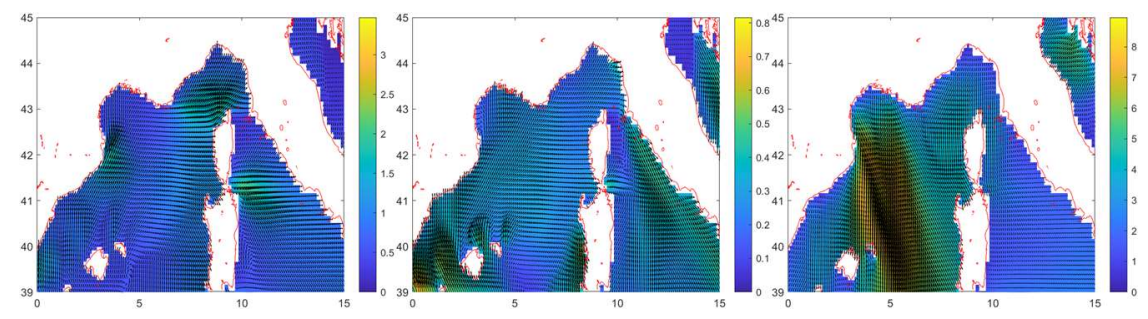

Fig.5. September - October - November. 


\section{Discussion}

Although the Mediterranean Sea is weighted and studied as a whole, the fact is that it is formed by twelve seas, most of them known by their own name, such as the Ligurian Sea, the Tyrrhenian Sea, the Adriatic Sea, the Jonic Sea, the Aegean Sea and the Marmara Sea. Of all these seas, the Ligurian and the Tyrrhenian Sea are the main seas of interest for this survey since the points studied are mostly placed in their waters and since different areas show climatological differences (Fig. 6).

The area 1 is in the Ligurian and the Tyrrhenian sea. These seas are characterised for being warm, even in the winter, but with torrential rains in the autumn. The area 2, located close to the Moroccan and Algerian coasts, presents some conditions distinct of the Mediterranean Sea, but without the peculiarities of his neighbouring zones. This is the reason why its values in the table fall in the in-between range compared with the other two areas. The area 3 is situated in the Mediterranean Sea, next to the Gulf of Lion and the Balearic Sea. The prevailing winds in this area of the golf are the North-wind, called the Tramontana, and the Mistral, which are the unchaining of the most important storms of the Western Mediterranean, with a swell that can exceed the 8 metres of height. A similar behaviour can be observed, although not as accused, in the interpolated wave field for the month of February (Fig. 2). Conversely, at the Balearic Sea episodes of rain are usually coupled with the arrival of the Leveche wind and the Levant wind, both debited of humidity when passing for the Mediterranean; they also bring very intense precipitations in autumn and occasional floods (Fig.4 and 5). 


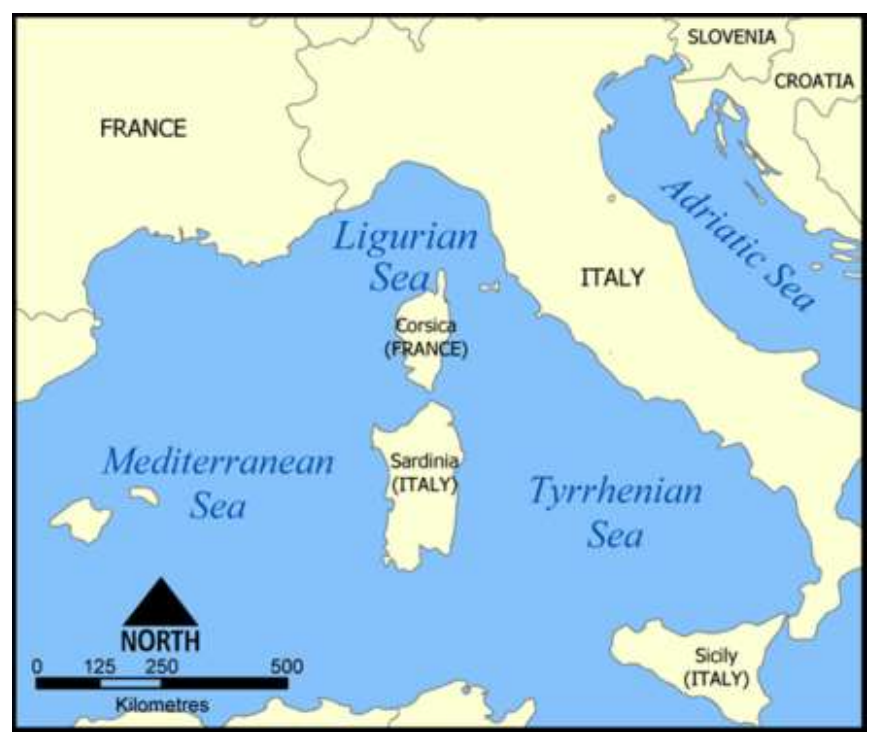

Fig.6. Ligurian, Tyrrhenian and Mediterranean Sea.

As it can be observed, the Mediterranean has a specific climate, with small peculiarities depending on the area of study. In general, it can be expected winters mildly cold, but humid and without rain, soft and rainy springs, warm and dry summers, and soft autumns with a high potential of torrential rains.

Regarding the effect that these conditions have for the navigation, the most affected months are January, February and November. The poor weather conditions in January and February are associated, as it has been said before, with the Tramontana and at the Mistral, as it can also be observed in the area 2 and 3, where most of the swell came from the North and the West. On the contrary, the adverse weather conditions of November, are caused by a north flux that provokes fanned strong winds from the North-West, due to the presence of an anticyclone in the Atlantic that is displaced to the north and the west of the Iberian Peninsula, and a low sited in the Gulf of Lion, that worsened the navigational conditions in the area. Of the three months, November is the most affected by the meteorological conditions. 
It is well known that the optimisation of routes is an effective method to operate the ships, increasing the safety and reducing the time of navigation and the consumption of fuel. There have been a lot of studies to develop methods of effective calculus to compound the optimal route. In the case of this project, the SIMROUTE fulfils two purposes: on the one hand, it samples the optimised route and provides the differences of time, consumptions and emissions, in comparison with the minimal distance route and, on the other hand, offers the interpolated wave fields for the dates chosen that can be used to compare the real conditions of the state of the sea with the statistical data gathered among the period 1958 - 2017. This comparison altogether with the knowledge on the climatology of the Mediterranean helps to represent the information visually and, allows to detect meteorological anomalies in the area through all the seasons.

\section{$6 \quad$ Results dissemination}

The internet is ever-present in our contemporary society, and recently has gained importance in the education field. Distance learning programs and online courses are proliferating, thanks to new education tools and online platforms. In fact, nowadays, higher education institutions need to address the problem of preparing students for the current professional requirements, which are continually changing, and which require a continuous update of their knowledge and skills [17].

Even when it has been argued [17] that online classes are neither practical nor effective and that they cannot, in any instance, substitute the traditional classroom environment, internet learning platforms make education accessible to all. Virtual communities are created to provide information and offer new tools to the students, and they have 
been expanding steadily in the last decade; sharing knowledge by means of Web-based interactions is a usual practice nowadays.

As a consequence of the digital revolution, and specially now, amid the COVID-19 pandemic, integrative and flexible forms of education are in great demand and represent an opportunity but also a challenge for the training professionals. The maritime sector is not an exception. In the early years, maritime education had been mainly focused on the vocational training of deck officers on board. However, as the maritime business evolved, a change in the maritime education curriculum started to be necessary.

To align maritime programs with the needs of maritime stakeholders, maritime studies have become an interdisciplinary academic field. Today, MET institutions must comply with the Standard Training and Certificate Watch keeping (STCW) Convention and Code. However, is also important to ensure that core subjects do not fade out under the integration of these new courses.

Over the last few years, the technological scenario has changed and communication between teachers, students and between students has become more fluid, through the platforms of each institution. These structured spaces make possible to propose learning activities, monitor each student and assess their performance while making the information about the centre available to the entire educational community.

An example of this is the Technical University of Catalonia, and by extension, the Barcelona School of Nautical Studies, which have enabled different platforms and dissemination tools. Among them there is the UPCommons Portal (Fig. 7), an open access portal that promotes academic and scientific communication at the University. There you can find published articles, final degree and master's theses, exams and 
various teaching materials, among others. However, in the setting of our institution, the students only participate in these platforms when it is the time to publish their theses. Apart from that, our students do not publish anything else on any other platform.

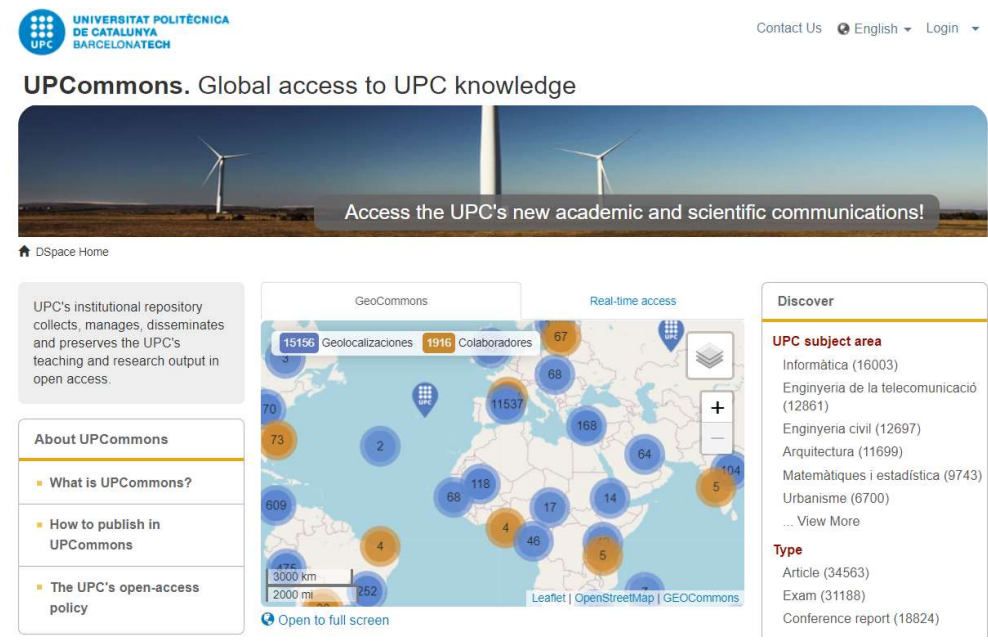

Fig.7. UPCommons Portal.

With the hard believing that student outputs are the result of a process that encourages learning, this project has its results presented as a participatory web format for dissemination and use as a didactic tool by the students. The platform is designed by teachers to use the SIMROUTE program, a tool that is already designed to work on the contents of the subject of Meteorology, along with the data collected in this study, to propose case study scenarios to the students. The results of these studies can be published on the website El Mediterrani (Fig.8) (www.elmediterrani.cat), and are available for consultation. 


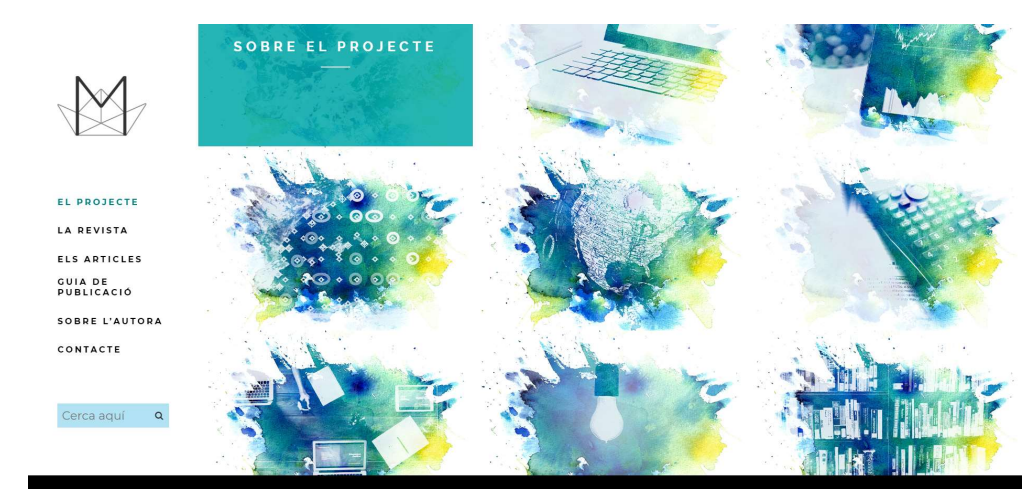

Fig.8. El Mediterrani, main page.

\section{Conclusions}

The data studied in this project give a detailed picture of the climatology of the western Mediterranean. The latter has a very similar climate in all its extensions, although with small peculiarities. In general, mildly cold winters can be expected, but humid and without rain, gentle and rainy springs, hot and dry summers, and soft autumns with a high risk of torrential rains. The climatological peculiarities of the western Mediterranean basin contribute directly to the generation of strong local winds, intense depressions, large floods and gusts.

The case study chosen is one of the short sea shipping routes in the Mediterranean, the Barcelona-Genoa line. As it has been said throughout the paper, short sea shipping is a crucial market in our sector. Its importance, as a more sustainable and environmentally friendly alternative, has been reiterated over the years, first with the publication of the White Paper in 2001, and then with the position taken by the EU in the face of the climate emergency. At this point, the use of this mode of transport is necessary, whether competitive or not, to address the problems posed by climate change. The full integration of this mode of transport with the logistics chain, together with the distribution of costs, are key factors for a safe, sustainable and efficient maritime transport. 
Despite the measures taken by the competent bodies, it has not been sufficient for a widespread implementation and, over the past decade, its growth has been derisory compared to that of the international maritime transport. However, it remains an indispensable tool in the fight against the climate emergency and is therefore defended in the context of the optimization of maritime routes and the advantages it entails.

The comparison between the statistical data and the interpolated wave fields of the Barcelona-Genoa route reinforce the image of the climatology of the western Mediterranean presented. Through the usage of the SIMROUTE software in conjunction with the database created it is possible to compare the real conditions of the state of the sea with the period 1958-2017 which allows to detect meteorological anomalies in the area across all seasons. The presentation of the results in web format offers a useful platform for the teaching of the Meteorology subject in our institution.

Academic publications in scientific journals are the proof of the generation of knowledge, a process that constitutes one of the main roles that the faculty must fulfil. The platform, presented in part with a similar format to that of a scientific journal, offers all those students in our faculty who are interested in publishing but have no experience, a space where they can learn. At the same time, teachers can propose activities related to academic production, which could then be published. So, this platform will be used to:

1. Promote academic production at the Barcelona School of Nautical Studies

2. Provide a safe and relaxed learning environment 
3. Create another source of knowledge available for the students while allowing them to share their research

4. Provide guidelines for students to start publishing in scientific journals

5. Offer the professors a platform to encourage students

Through computed-supported collaborative learning, students will acquire life-long skills and they will participate of the activities of their institution.

\section{References}

1. Grosso, M., Lynce, A. R., Silla, A., \& Vaggelas, G. K.: Short Sea Shipping, intermodality and parameters influencing pricing policies: the Mediterranean case. NETNOMICS: Economic Research and Electronic Networking, 11(1), 47-67 (2010)

2. Psaraftis, H. N.: Challenges in European Short Sea Shipping. In IMAM 2009 Conference, Istanbul (pp. 13-15) (2009)

3. Douet, M., \& Cappuccilli, J. F.: A review of Short Sea Shipping policy in the European Union. Journal of Transport Geography, 19(4), 968-976 (2011)

4. Castells, M., \& Oses, F. X. M.: Studies of suitability on short sea shipping routes in SW Europe. Journal of Maritime Research, 3(2), 43-52 (2006)

5. Musso, E., \& Marchese, U.: Economics of short sea shipping. The handbook of maritime economics and business, 280-304 (2002)

6. Hjelle, H. M., \& Fridell, E.: When is short sea shipping environmentally competitive? Environmental Health-Emerging Issues and Practice, 3-20 (2012)

7. Christodoulou, A., \& Woxenius, J.: Sustainable short sea shipping (2019)

8. Martín Vide, J., \& Olcina Cantos, J.: Tiempos y climas mundiales: climatología a través de mapas del tiempo e imágenes de satélite, pàg. 165-167 (1996)

9. Jansà Clar, A.: Meteorología y climatología mediterráneas (1980)

10. Benítez, N., Campanario, S., Cuaresma, V., Digeuez, M. \& Morilla, A.: Clima Mediterráneo (2012) 
11. Pastor, F., Valiente, J. A., \& Palau, J. L.: Sea surface temperature in the Mediterranean: Trends and spatial patterns (1982-2016). In Meteorology and climatology of the Mediterranean and black seas (pp. 297-309). Birkhäuser, Cham (2019)

12. Iona, A., Theodorou, A., Sofianos, S., Watelet, S., Troupin, C., \& Beckers, J. M.: Mediterranean Sea climatic indices: monitoring long-term variability and climate changes. Earth System Science Data, 10(4), 1829-1842 (2018)

13. i Clar, A. J. (1995). Peculiaritats meteorològiques de la Mediterrània Occidental. Butlletí de les Societats Catalanes de Física, Química, Matemàtiques i Tecnologia, 9197.

14. Sala, J. Q., Chiva, E. M., \& Barberá, J. E.: La evolución de las precipitaciones en la cuenca occidental del mediterráneo: ¿̇endencias o ciclos? Investigaciones Geográficas (Esp), (24), 17-35 (2000)

15. Frigola Ferrer, J. I.: Variabilitat climàtica ràpida a la conca occidental del Mediterrani: registre sedimentològic (2012)

16. Medda, F., \& Trujillo, L..: Short-sea shipping: an analysis of its determinants. Maritime Policy \& Management, 37(3), 285-303 (2010)

17. Marzano, G., \& Ochoa-Siguencia, L.: Challenges of web-based participatory learning. In Society. Integration. Education. Proceedings of the International Scientific Conference (Vol. 2, pp. 458-467) (2017) 